\title{
PLANEJAMENTO AMBIENTAL DOS RECURSOS HÍDRICOS NA BACIA DO RIBEIRÃO ANHUMAS, MUNICÍPIO DE ANHUMAS - SP.
}

Bruno Magro Rodrigues ${ }^{1,}$ Ana Paula de Lima $\operatorname{Costa}^{1}$, Marcos Norberto Boin ${ }^{2}$.

${ }^{1}$ Discente do curso de graduação em Engenharia Ambiental - UNOESTE. ${ }^{2}$ Docente - UNOESTE. E-mail: b_magro@hotmail.com

\section{RESUMO}

O presente trabalho realizou uma análise dos recursos hídricos da bacia do ribeirão Anhumas, tendo como resultado parcial a análise ambiental do córrego do Cambuí, integrando os principais componentes da paisagem; comparando-se as características das águas provenientes da contribuição antrópica com a qualidade natural das mesmas, no município de Anhumas. Trazer reflexões sobre a sustentabilidade ambiental e os usos do solo com enfoque sempre na disponibilidade e qualidade da água. Assim, com o diagnóstico da situação do uso do solo e de eventuais lançamentos de efluentes na bacia em questão, pretende-se neste trabalho, apontar as condições em que se encontram os recursos hídricos na bacia do ribeirão Anhumas, município de Anhumas, com relação a sua qualidade da água e ambiental. Acompanha carta hidrológica e carta representativa da bacia do córrego do Cambuí, incluindo usos do solo e faixas ripárias.

Palavras-chave: Recursos hídricos; Qualidade das águas; bacia do ribeirão Anhumas; bacia do córrego do Cambuí.

\section{INTRODUÇÃO E OBJETIVO}

A transformação de ambientes naturais em áreas de cultivo, de pecuária, urbanas e industriais, principalmente a partir do Século $X X$, vem acompanhada de um domínio e eficiência tecnológica que, no entanto, ainda encontram-se distantes de uma relação sustentável com o meio, causando modificações danosas aos sistemas ambientais (GUERRA \& MARÇAL, 2006), revertidos na própria humanidade, com perdas de vidas e bens materiais em alagamentos e deslizamento de terra, como também na perda progressiva da fertilidade natural e remoção de camadas do solo, além da degradação qualitativa e quantitativa dos recursos hídricos para continuidade das atividades antrópicas.

A bacia hidrográfica é definida como área que circunscreve um território drenado por um rio principal, seus afluentes e subafluentes, permanentes ou intermitentes, funcionando como um sistema aberto (SANTOS, 2004). A bacia constitui um sistema natural bem delimitado no espaço, em que cada um dos elementos, matérias e energias presentes no sistema apresentam uma função própria e estão estruturados e intrinsecamente relacionados entre si (CHRISTOFOLETTI, 1980), permitindo que essas interações sejam mais facilmente interpretadas, sendo por esses fatores, utilizada como unidade territorial em planejamento ambiental. 
As bacias hidrográficas são de grande importância em estudos ambientais e consideradas como unidade de pesquisa de diversos assuntos, isto se deve à relevância de sua dinâmica e à interação dos elementos químicos, físicos e biológicos existentes, que interferem diretamente na sociedade.

O homem interfere no meio ambiente, criando novas situações ao construir e reordenar o espaço físico de acordo com seus interesses, fazendo, muitas vezes, com que haja uma utilização incorreta ou inadequada dos recursos naturais.

O município de Anhumas possui uma área total de $321 \mathrm{~km}^{2}$, está situado no oeste do estado de São Paulo cujas coordenadas do ponto central da cidade de acordo com a imagem do Google Earth são: Latitudinais 22 17' 45"S e Longitudinais 51ㅇ 23' 08"W.

A área total da bacia do ribeirão Anhumas é de 182,96 km², sendo que o canal principal, que nasce ao norte da cidade de Anhumas, percorre 31.040 metros até a divisa sul do município.

Como destaca Guerra \& Marçal (2006), a identificação de uma unidade ambiental, ou unidade de paisagem, com suas respectivas intervenções sofridas ao longo dos anos pela sociedade permite a aplicação de métodos e técnicas necessários à sua análise, proporcionando a sua identificação, classificação, diagnóstico e prognóstico da paisagem.

A análise integrada da paisagem aplicada ao planejamento ambiental de bacia hidrográfica pode contribuir para subsidiar a gestão dessas áreas através do planejamento do uso dos recursos naturais, considerando as potencialidades e fragilidades dos sistemas ambientais (ROSS, 2009, p.47).

O planejamento ambiental deve adequar a estrutura econômica local à dinâmica natural, buscando intervir e disciplinar o uso da terra, surgindo como uma proposta de superação da inadequada utilização dos recursos naturais e da distribuição e organização da sociedade e das atividades econômicas sobre o território.

De acordo com CHRISTOFOLETTI (1980, p. 52):

Todos os acontecimentos que ocorrem na bacia de drenagem repercutem, direta ou indiretamente, nos rios. As condições climáticas a cobertura vegetal e a litologia são fatores que controlam a morfogênese das vertentes e, por sua vez, o tipo de carga detrítica a ser fornecida aos rios. 0 estudo e a análise dos cursos de água só podem ser realizados em função da perspectiva global do sistema hidrográfico.

Embora existam leis que estabeleçam estudos de impactos ambientais, limites para ocupações e exploração dos recursos naturais, as gestões políticas e o economicismo cego 
proporcionam ocupações e transformações danosas ao meio ambiente. Um dos reflexos dessa gestão inadequada encontra-se na bacia do ribeirão Anhumas, na qual as atividades antrópicas desenvolvidas na bacia ultrapassam a tolerância do ecossistema presente, resultando no desencadeamento de processos erosivos, removendo camadas do solo, assoreando os corpos d'água, e contaminando as águas da bacia hidrográfica.

O presente trabalho teve como objetivo realizar uma análise da qualidade ambiental dos recursos hídricos da bacia do Córrego do Cambuí, integrando-os aos principais componentes da paisagem; geologia; pedologia; geomorfologia; vegetação; e uso e ocupação do solo, de forma a avaliar a qualidade dos recursos hídricos na bacia hidrográfica do Córrego do Cambuí, no município de Anhumas.

O seguinte trabalho é um resultado parcial de um projeto de iniciação científica desenvolvida, onde se aborda o planejamento ambiental dos recursos hídricos na bacia do ribeirão Anhumas. Este projeto é desenvolvido no Núcleo de Estudos Ambientais e Geoprocessamento NEAGEO, em parceria com o Mestrado em Meio Ambiente e Desenvolvimento Regional MMADRE, da Universidade do Oeste Paulista - UNOESTE.

\section{METODOLOGIA}

Utilizou-se de técnicas de geoprocessamento e sensoriamento remoto, através do Programa Spring 5.2.3, sobre imagens disponibilizadas no satélite Spot-5, Sensor RHG e cartas topográficas do IBGE, tendo como objeto de estudo a bacia hidrográfica do Córrego do Cambuí, localizada no município de Anhumas, estado de São Paulo, onde foram levantadas as seguintes informações: limites da bacia hidrográfica, hidrografia, áreas de várzeas, áreas úmidas (lençóis suspensos), pastagem, vegetação natural, cultura anual, reflorestamento de nativas, reflorestamento de exóticas e cana de açúcar.

Criou-se sobre as imagem as categorias e planos de informações necessárias para a confecção das cartas, realizando as vetorizações desejadas, trabalhando com a escala 1:3.000, sendo vetorizados a hidrografia, massas d'água, lençóis suspensos, limite da bacia, vegetação, plantações e pastagens. Uma vez organizadas e levantadas as cartas citadas anteriormente, consolidou-se uma carta a que integrasse a síntese destas unidades, utilizando como referência os estudos realizados por CRJC elaborou-se duas cartas, na escala 1:50.000, que nos permitiram fazer uma comparação do uso atual da bacia hidrográfica versus o uso ideal da mesma, mantendo-se na carta as mesmas larguras dos estudos realizados por CRJC, apresentados na figura 1, a seguir. 


\section{RESULTADOS}

Após a confecção das duas cartas, pode-se realizar um estudo comparativo do uso do solo na bacia do Córrego do Cambuí, levando-se em consideração o uso e manejo do solo que ocorrem atualmente e os aspectos e impactos que essa utilização pode causar para os recursos hídricos, e todo o ecossistema da bacia hidrográfica. Na Figura 1 podemos visualizar a hidrografia da bacia do Córrego do Cambuí, bem como seus lençóis suspensos, massas d'água e áreas de várzea.

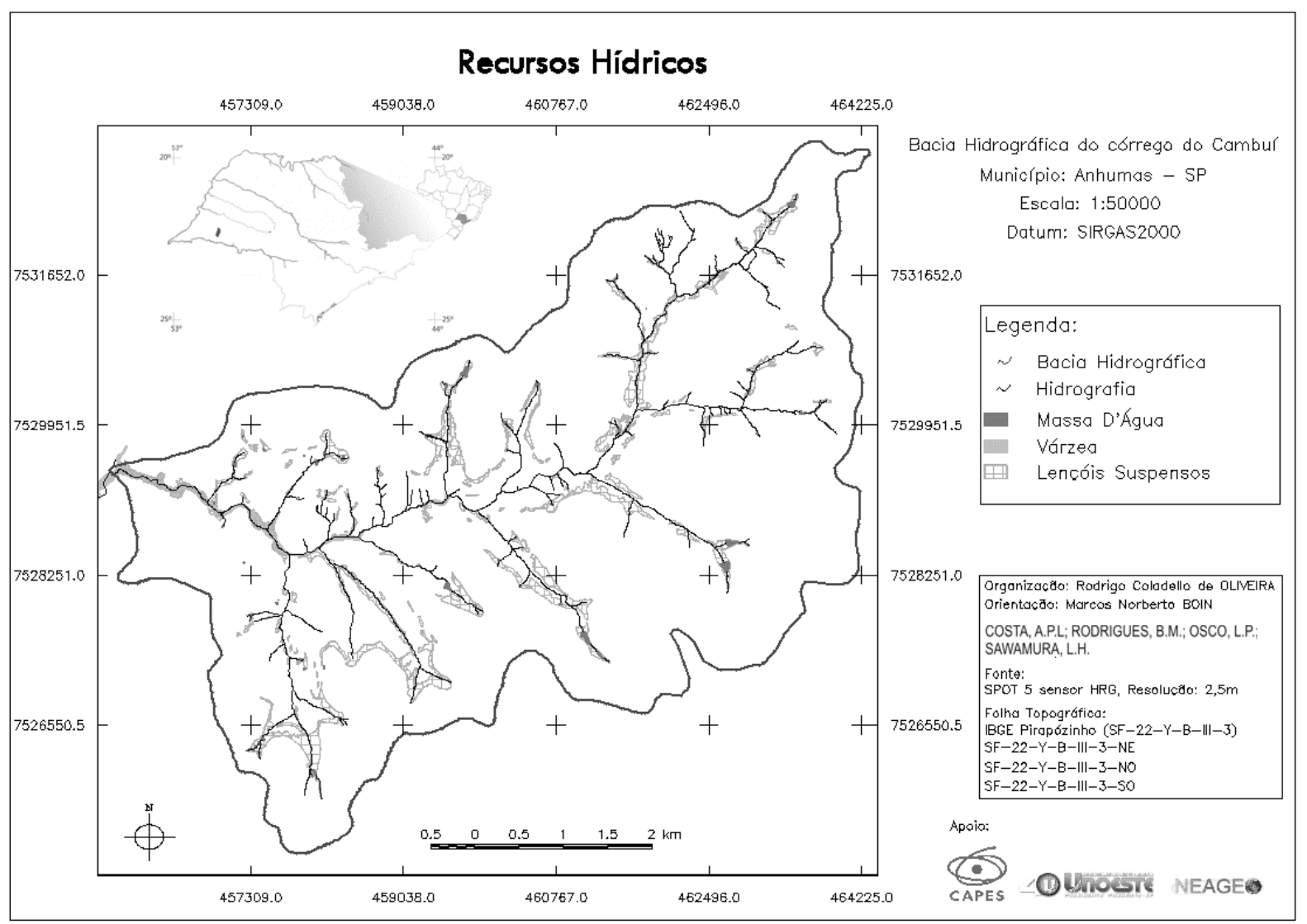

Figura 1. Carta hidrológica da bacia do córrego do Cambuí

A Legislação Brasileira (Códigos Florestais) estabeleceu uma série de funções voltadas à proteção dos recursos hídricos por meio da manutenção de zonas ripárias, propondo larguras mínimas para as diferentes situações de ocorrência dos recursos hídricos. Estas funções se aproximam das proposições teóricas sobre a largura das faixas de vegetação e sua eficiência ambiental na proteção dos corpos d'água, utilizadas neste trabalho.

De acordo com Silva (2003), a zona ripária possui algumas funções, são elas: estabilização de taludes e encostas; manutenção da morfologia do rio e proteção contra enchentes; retenção de sedimentos e nutrientes; mitigação da temperatura e da água e do solo; fornecimento de 
alimento e habitat para criaturas aquáticas; manutenção de corredores ecológicos; paisagem e recreação; fixação do gás carbônico; e interceptação de escombros rochosos. As faixas de vegetação, portanto, têm por função geral a manutenção e o controle da qualidade do corpo hídrico.

A Figura 2 relata sobre as faixas ideais de vegetação ripária que devem ser seguidas para que se mantenham as qualidades naturais necessárias a um corpo hídrico.

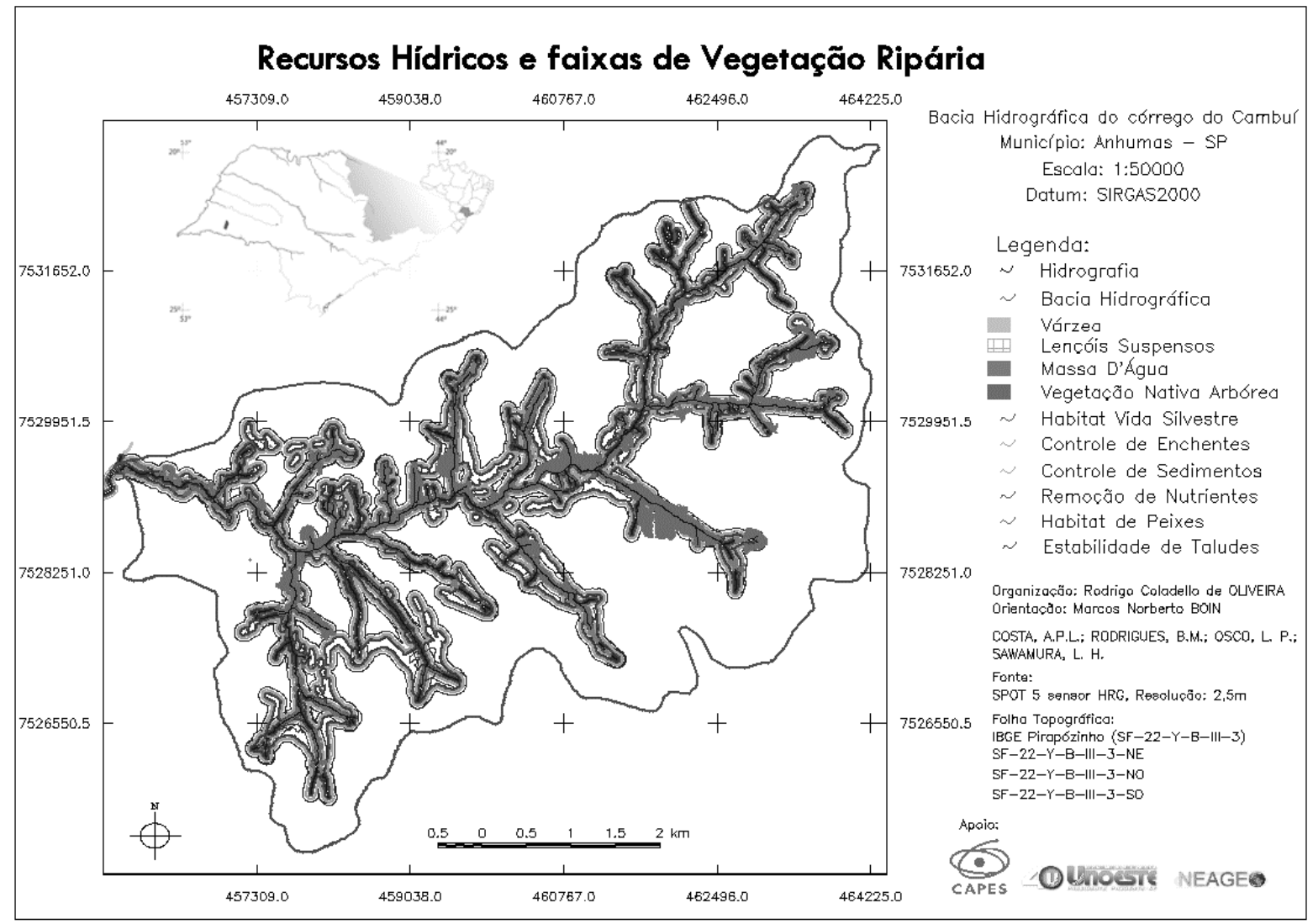

Figura 2. Carta representativa da bacia do córrego do Cambuí, contendo a hidrografia e as respectivas faixas de zonas ripárias no município de Anhumas - SP.

De acordo com as faixas de eficiência da vegetação ripária evidenciadas na Figura 2, observaram-se conflitos entre os usos e ocupações existentes no interior da bacia com as faixas de proteção dos corpos d'água. Os maiores conflitos estão relacionados aos afloramentos do freático, que na área em questão são representados predominantemente pelos lençóis suspensos em meia encosta pela facilidade de exploração do entorno e mesmo de seu interior.

Ao longo dos cursos d'água superficiais, junto aos fundos de vales, ocorrem porções de vegetação nativas em alguns trechos de suas margens, e em alguns casos a vegetação cobre todas as faixas de proteção dos corpos d'água, tais como: estabilidade de taludes, habitat de peixes, remoção de nutrientes, controle de enchentes e habitat da vida silvestre, entretanto estes trechos 
são restritos. Observou-se em algumas faixas de proteção dos corpos d'água a existência de áreas de culturas que ocupam as áreas de preservação permanente, e em alguns casos a cultura está a menos de 15 metros do leito do rio. Tal fato remete a possibilidade da contaminação do corpo hídrico por meio de materiais xenobióticos, como agrotóxicos, vinhaça e fertilizantes sintéticos, pois a vegetação atua como um filtro biológico de sedimentos e materiais diversos.

Além dos fatores de contaminação química do rio, é observada a interferência na estabilidade dos taludes em áreas próximas ao leito do rio, onde não há a presença da vegetação ripária. Em áreas de 15 a 20 metros de proximidade dos cursos d'água, onde não há a presença de vegetação, percebe-se a interferência na vida aquática, visto que a vegetação influi diretamente na temperatura da água e quantidade de oxigênio dissolvido na mesma. A vegetação por possuir um potencial de absorção da água da chuva, atua também como amortecedora da energia da água pluvial e assim diminui o tempo de escoamento superficial e consequentemente reduz a chance de enchentes, visto que em faixas com largura menor que 60 metros de vegetação em torno dos rios, a probabilidade de ocorrência de enchentes em seu percurso é maior.

Diante do quadro de degradação dos ecossistemas ribeirinhos na bacia do Córrego do Cambuí, com a ocupação das faixas de proteção dos recursos hídricos, pode-se concluir que os recursos hídricos nesta bacia não têm qualidade ambiental e sustentabilidade. Os processos de solapamento das margens, o assoreamento, a entrada de nutrientes e consequentemente a eutrofização e degradação dos habitat dos peixes e ausência dos habitat da vida silvestre (flora e fauna), conferem a esta bacia uma baixa qualidade ambiental dos recursos hídricos.

Portanto, somente a adoção de medidas de preservação destas zonas ripárias, garantir-seia as condições mínimas ideais para a manutenção adequada dos ecossistemas da bacia hidrográfica estudada, bem como a conservação da fauna, flora, solo e corpos hídricos superficiais ou subterrâneos.

\section{REFERÊNCIAS}

BRASIL. Código Florestal, Lei 12.561 de maio de 2012.

CHRISTOFOLETTI, A. Geomorfologia. 2a ed. São Paulo: Edgard Blücher, 1980.

GUERRA, A. J. T.; MARÇAL, M. S. Geomorfologia Ambiental. Rio de Janeiro: Bertrand Brasil, 2006.

ROSS, J. S. Geomorfologia: ambiente e planejamento. 5aed., São Paulo, contexto, 2009.

SANTOS, R. F. Planejamento Ambiental: teoria e prática. São Paulo: Oficina de textos, 2004. 
Encontro de Ensino, Pesquisa e Extensão, Presidente Prudente, 21 a 24 de outubro, 2013

SILVA, R. V. Estimativa de largura de faixa vegetativa para zonas ripárias: Uma revisão. I Seminário de Hidrologia Florestal: Zonas Ripárias - Alfredo Wagner/SC, 2003. 